\title{
Clinical Profile and Co-morbidities of Conduct Disorder and Oppositional Defiant Disorder in Bangladesh
}

\author{
SESYED $^{\mathrm{a}}$, MSIMULLICK ${ }^{\mathrm{b}}$
}

Summary:

Background: Among juvenile behavior disorders, Conduct Disorder and Oppositional Defiant Disorder (ODD) are predominant ones and are of great concern because of their high degree of impairment.

Materials \& Methods: This descriptive cross-sectional study was conducted in the department of Psychiatry, Bangabandhu Sheikh Mujib Medical University and National Institute of Mental Health, Dhaka, during the period from August 2011 to November 2012 with sample size of 81. During data collection, semi-structured questionnaire designed by the researcher containing socio-demographic variables and Developments and Well-Being Assessment $(D A W B A)$ - self, parent and teacher version were used.

Results: Symptom profile showed that oppositional symptoms had no significant age or gender difference but aggressive symptoms, status offenses and property offenses were clearly more common among boys. Younger boys with Conduct

Introduction:

Behaviours that violate the rights of others and/or that bring the individual into significant conflict with societal norms or authority figures are called disruptive behaviours and worldwide, disruptive behaviour disorders (Conduct Disorder and Oppositional Defiant Disorder) are amongst the most frequent reasons for which a given youth is referred for mental health evaluation. The essential feature of Conduct Disorder is a repetitive and persistent pattern of behavior in which basic rights of others or major age appropriate societal

a. Dr. Sifat E Syed. Assistant Professor. Department of Psychiatry. Bangabandhu Sheikh Mujib Medical University, Shahbagh, Dhaka.

b. Prof. Mohammad SI Mullick. Professor of Child and Adolescent Psychiatry. Department of Psychiatry. Bangabandhu Sheikh Mujib Medical University, Shahbagh, Dhaka.

Address of Correspondence: Dr. Sifat E Syed, Assistant Professor. Department of Psychiatry. Bangabandhu Sheikh Mujib Medical University, Shahbagh, Dhaka. E-mail: sifat.syed@yahoo.com Phone: 01745773664

Received: 22 March, 2018

Accepted: 20 Oct., 2019 disorder showed more aggressive symptoms, but status offense was more prevalent in older age group. Property offenses showed no age difference. Psychiatric co-morbidity was present in $48.1 \%$ respondents, among them; AttentionDeficit/Hyperactivity Disorder (ADHD) was highest (24.7\%). ADHD was more prevalent in children with ODD and Major Depressive Disorder was more common in Conduct disorder. Total percentage of anxiety disorders was $14.8 \%$.

Conclusion: This was the first study in Bangladesh exploring the clinical profiles of Conduct disorder and Oppositional defiant disorder in hospital setting. Absence of control group and city based study places were the limitations of the research.

Key words: Conduct Disorder, Oppositional Defiant Disorder (ODD), juvenile behavior disorders,

(J Bangladesh Coll Phys Surg 2020; 38: 29-34)

DOI: http://dx.doi.org/10.3329/jbcps.v38i1.44686

rules or norms are violated. Oppositional Defiant Disorder (ODD) involves a pattern of angry/irritable mood, argumentative/defiant behavior and vindictiveness and is often considered as a precursor/ prodrome of Conduct disorder. ${ }^{1}$

Both disorders are classified under the broad heading of Attention-Deficit and Disruptive Behavior Disorders in Diagnostic and Statistical Manual for mental disorders $-4^{\text {th }}$ edition (DSM-IV). ODD is considered to be a subsyndrome of Conduct disorder in ICD-10 but DSM-IV puts ODD as a separate diagnosis. ${ }^{2}$

Conduct problems are common mental health concern in childhood, affecting $5-8 \%$ of the population. ${ }^{3}$ Longterm outcomes are very poor, with three- to six fold increases in the prevalence of adult criminal violence, drug misuse, school failure, teenage pregnancy and unemployment. ${ }^{4}$ This problem is amplified in low- and middle-income countries where child mental health services are extremely limited. ${ }^{5-6}$

In Bangladesh, the prevalence of Conduct Disorder and Oppositional Defiant Disorder was 2.9\% and 5.9\% respectively in 5-10 years old children and prevalence 
in slum areas was much higher than those residing in rural and urban areas. ${ }^{7}$ In contrast, a nationwide survey found $1.0 \%$ prevalence of each disorder in a community survey. ${ }^{8}$

A meta-analytic summary by Frick et al (1994) yielded four clusters of symptoms and the four clusters areoppositional behaviours, aggression, property offenses and status offenses. ${ }^{9}$ DSM-IV also categorized the symptoms of Conduct disorder under four sub-headings which is quite similar to that of the above mentioned clusters.

Early detection and management of Conduct Disorder and Oppositional Defiant Disorder can potentially prevent psycho-socialconsequences in adult life. It was found in researches that conduct symptoms were the most robust predictor of severe and persistent form of anti-social behavior in later life ${ }^{10}$ whereas ODD symptoms were significantly associated with later depressive symptoms (particularly among girls). ${ }^{11}$ There is evidence that early school-based intervention in a middle-income country substantially reduced child conduct problems. ${ }^{12}$ But, worldwide, lack of data gathering capacity was found to be a major deficit for managing child and adolescent mental health disorders. ${ }^{5}$ This research was aimed to collect credential baseline information in this country which will assist to carry out further research in this field.

\section{Materials and Methods:}

This was a descriptive cross sectional study conducted during the period from August 2011 to November 2012. Children and adolescents aged from 5-17 years diagnosed as Conduct disorder or Oppositional defiant disorder were taken as sample from Dept. of Psychiatry, Bangabandhu Sheikh Mujib Medical University (BSMMU), Dhaka (both inpatient and outpatient department) and Child guidance clinic (OPD), National Institute of Mental Health(NIMH), Dhaka. The sample size was 81, among them, 55 were from BSMMU and 26 were from NIMH. During data collection, semi-structured questionnaire designed by the researcher containing socio-demographic variables was used and Developments and Well-Being Assessment (DAWBA) - self, parent and teacher versions were used to generate DSM-IV diagnosis.

In the first visit, DAWBA parents version and self version (in respondents over 11 years) was applied. Teacher's version was supplied to the parents and was collected via parents during the second visit. Response from either school teacher or house teacher's was accepted. Some of the respondents did not came back for further follow up and some of them stopped going to school, that's why teacher's version could not be applied. Some parents refused to convey the sheet to the teacher. The percentage of missing teacher data was $62 \%$.

DAWBA is an internationally well accepted research instrument and a novel package of questionnaires, interviews and rating techniques designed to generate DSM-IV and ICD-10 psychiatric diagnoses among children and adolescents of 5 to 16 years (extended up to 18 years). This instrument has been translated in Bangla and standardized and validated by Mullick MSI et al. ${ }^{7}$ The validated Bangla version of DAWBA was used in this study. Data was analyzed using Statistical Package for Social Science (SPSS), version 17.0 for Windows.

\section{Results:}

The study showed that among 81 samples, 32 respondents had Oppositional Defiant Disorder and 49 had Conduct Disorder. There was male preponderance and the malefemale ratio was 2.5:1. Symptoms were analyzed according to four clusters of behavior problems (Table 1).

Table-I

The four clusters of behavioural problems.

\begin{tabular}{ll} 
Clusters & Symptoms \\
\hline Cluster- I: Oppositional & Temper outbursts, Arguing, \\
behaviours & $\begin{array}{l}\text { Defiance, } \\
\text { Annoy others, Blame others, } \\
\text { Touchy, } \\
\text { Angry, Spiteful, Vindictiveness }\end{array}$ \\
& $\begin{array}{l}\text { Bullying, Start fights, Used } \\
\text { Weapon, }\end{array}$ \\
Cluster- II: Aggression & $\begin{array}{l}\text { Forced sex, Cruelty, Hurt } \\
\text { animals, }\end{array}$ \\
& Mugging. \\
& $\begin{array}{l}\text { Frequent lying, Stealing, } \\
\text { Breaking in, } \\
\text { Vandalizing, Setting fire }\end{array}$ \\
& $\begin{array}{l}\text { Staying out late, Running away } \\
\text { from home, Truancy. }\end{array}$ \\
\hline
\end{tabular}

Present study found that girls with ODD had more 
oppositional symptoms than boys but the difference was not significant $(p=0.08)$. Among the respondents with Conduct Disorder, majority had Oppositional symptoms $(>70 \%)$ and girls showed a slightly higher rate of oppositional behaviors than boys (Figure 1) but the difference was not significant. Aggressive symptoms were common in boys and the difference was highly significant ( $\mathrm{p}=.001)$ (Table 2 ). Among the property offenses, lying and stealing was common among girls. Status offenses were more common in boys and the difference was statistically significant $(\mathrm{p}=0.05)$ (Table 3). This study showed that younger children with Conduct disorder showed more aggressive symptoms than older and the difference was statistically significant $(p=0.026)$ (Table 4). Status offense was slightly more prevalent in older age group and property offense showed no age difference (Figure 2). About 39 (48.1\%) children/adolescents had one or more co-morbidities along with ODD/Conduct disorder (Table 5). Attention Deficit/Hyperactivity Disorder (ADHD) was present in $43.8 \%$ of children with ODD and $12.3 \%$ with conduct disorder. Major depressive disorder was present in $22.4 \%$ of conduct disorder and in $3.1 \%$ of ODD population. Total percentage of anxiety disorders (Obsessive Compulsive Disorder, Separation anxiety,
Speific phobia) was $14.8 \%$. Apart from DSM-IV diagnosis, many girls with Conduct disorder $(60 \%)$ had history of self-harm.

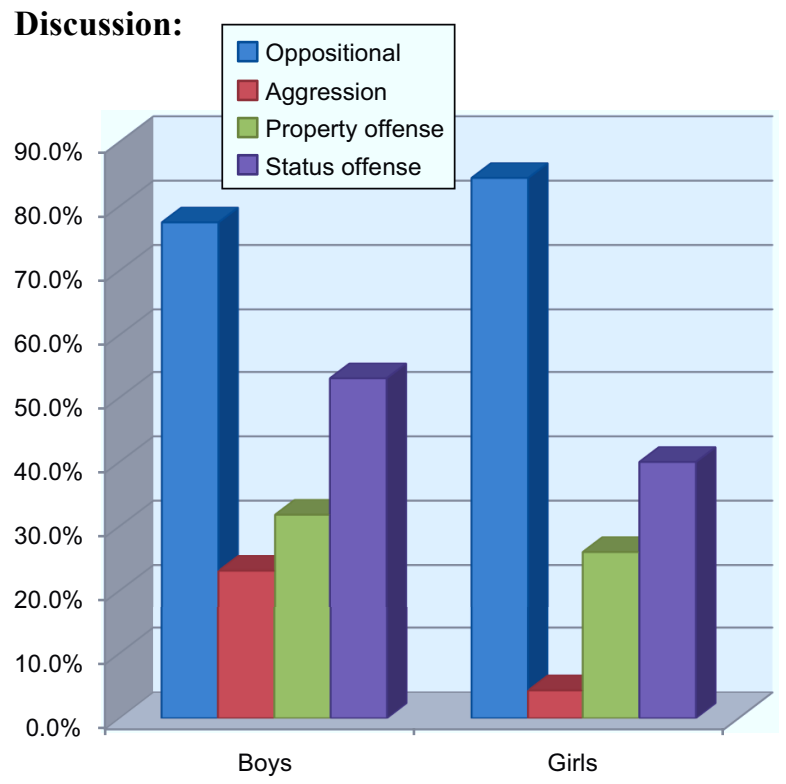

Fig.-1: Multiple bar diagram showing mean percentage of symptom clusters in boys and girls with conduct disorder $(n=49)$.

Table-II

Comparison of aggressive symptoms in boys and girls with Conduct disorder ( $n=49)$

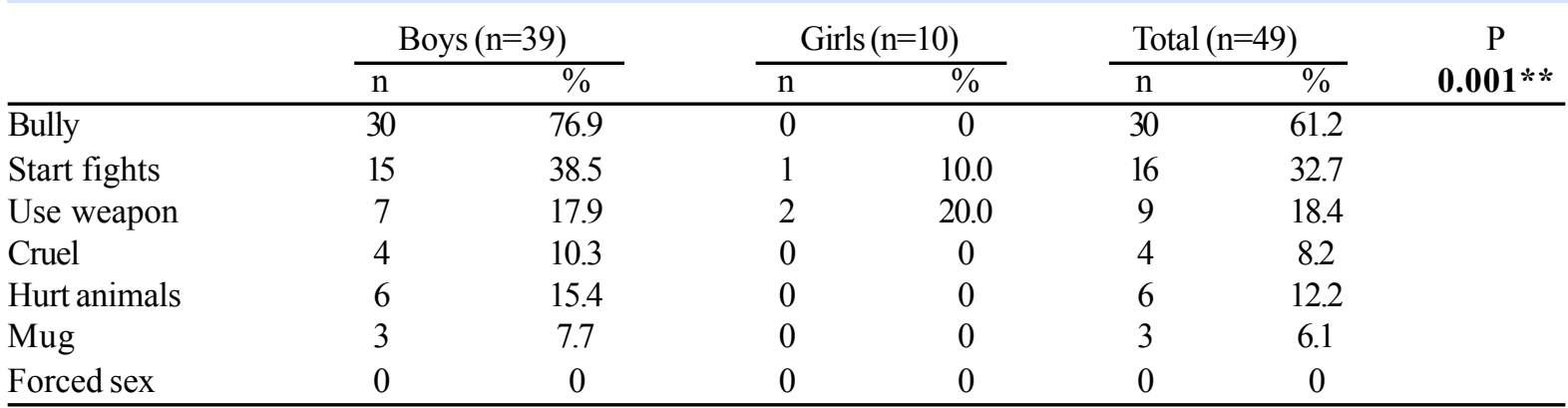

$\mathrm{c}^{2}=23.827, \mathrm{df}=6$

\section{Table-III}

Comparison of status offenses in boys and girls with Conduct disorder $(n=49)$

\begin{tabular}{|c|c|c|c|c|c|c|c|}
\hline \multirow[t]{2}{*}{ Symptom } & \multicolumn{2}{|c|}{ Boys $(n=39)$} & \multicolumn{2}{|c|}{ Girls $(n=10)$} & \multicolumn{2}{|c|}{ Total $(n=49)$} & \multirow{2}{*}{$\begin{array}{c}\mathrm{P} \\
0.05 *\end{array}$} \\
\hline & $\mathrm{n}$ & $\%$ & $\mathrm{n}$ & $\%$ & $\bar{n}$ & $\%$ & \\
\hline Stay out late & 24 & 61.5 & 6 & 60.0 & 30 & 61.2 & \\
\hline Run away & 13 & 33.3 & 2 & 20.0 & 15 & 30.6 & \\
\hline Truant/bunk & 25 & 64.1 & 4 & 40.0 & 29 & 59.2 & \\
\hline
\end{tabular}

$\mathrm{c}^{2}=7.527, \mathrm{df}=3$ 
Table-IV

Comparison of aggressive symptoms in two age groups of Conduct disorder $(n=49)$

\begin{tabular}{|c|c|c|c|c|c|c|c|}
\hline & \multicolumn{2}{|c|}{ Age $<11$ yrs $(n=6)$} & \multicolumn{2}{|c|}{ Age $\geq 11$ yrs $(n=43)$} & \multicolumn{2}{|c|}{ Total $(n=49)$} & \multirow{2}{*}{$\frac{\mathrm{P}}{0.026}$} \\
\hline & $\mathrm{n}$ & $\%$ & $\mathrm{n}$ & $\%$ & $\mathrm{n}$ & $\%$ & \\
\hline Bully & 6 & 100.0 & 24 & 55.9 & 30 & 61.2 & \\
\hline Start fights & 3 & 50.0 & 13 & 30.3 & 16 & 32.7 & \\
\hline Use weapon & 2 & 33.3 & 7 & 16.3 & 9 & 18.4 & \\
\hline Cruel & 2 & 33.3 & 2 & 4.7 & 4 & 8.2 & \\
\hline Hurt animals & 4 & 66.7 & 2 & 4.7 & 6 & 12.2 & \\
\hline Mug & 0 & 0 & 3 & 7.0 & 3 & 6.1 & \\
\hline Forced sex & 0 & 0 & 0 & 0 & 0 & 0 & \\
\hline
\end{tabular}

$c^{2}=11.092, d f=4$

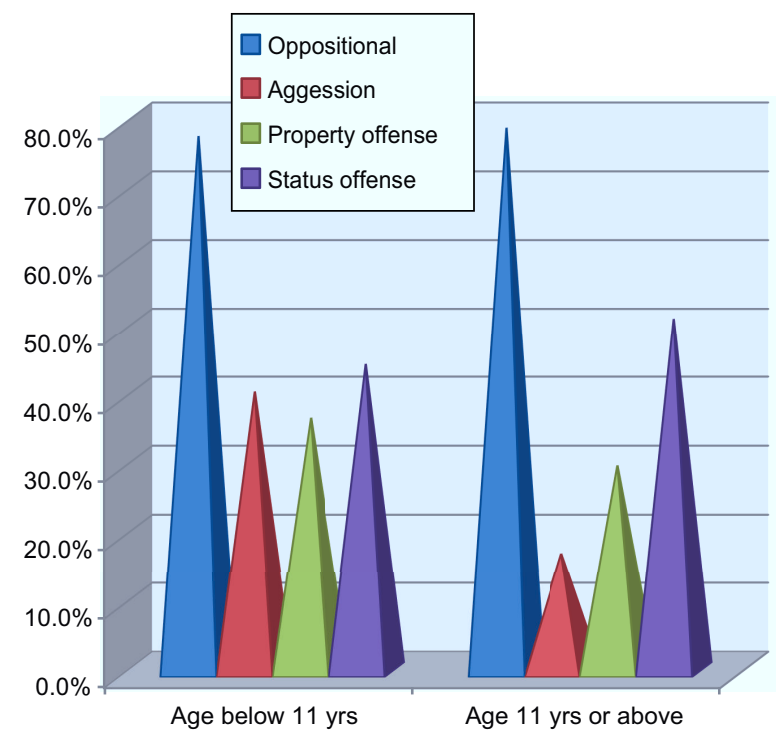

Fig.-2 : Pyramid diagram showing mean percentage of symptom clusters in two age groups of conduct disorder $(n=49)$

Table-V

Frequency distribution of the co-morbidities $(n=81)$

\begin{tabular}{lcccccc} 
& \multicolumn{2}{c}{$\mathrm{ODD}(\mathrm{n}=32)$} & \multicolumn{2}{c}{$\mathrm{CD}(\mathrm{n}=49)$} & \multicolumn{2}{c}{ Total $(\mathrm{n}=81)$} \\
& $\mathrm{n}$ & $\%$ & $\mathrm{n}$ & $\%$ & $\mathrm{n}$ & $\%$ \\
\hline No co-morbidity & 13 & 40.6 & 29 & 59.2 & 42 & 51.9 \\
ADHD & 14 & 43.8 & 6 & 12.3 & 20 & 24.7 \\
Major depressive disorder & 1 & 3.1 & 11 & 22.4 & 12 & 14.8 \\
Anxiety disorders & 8 & 25.0 & 4 & 8.2 & 12 & 14.8 \\
\hline
\end{tabular}

This study was aimed to obtain credible baseline data about Conduct Disorder and Oppositional Defiant Disorder and to find out the common co-morbidities of these two disorders which can be of great help in clinical setting. We distinguished four types of symptoms/ behavioral problems based on a meta-analysis of 44 factor analytic studies of more than 28000 youths. ${ }^{9}$ This meta-analysis yielded four clusters of behavior problems: oppositional behavior, aggressive conduct 
problems, property offenses, and status offenses (Table 1). The same clusters were confirmed in two independent studies. ${ }^{13-14}$

We found that oppositional symptoms were more frequently present in girls with Oppositional Defiant Disorder than boys but the difference was not significant and there was no age difference as well. Lahey et al (2000) also revealed that there were no gender differences in oppositional behavior between two sexes. ${ }^{13}$ Respondents with ODD did exhibit some of the conduct symptoms (eg- lying, stealing, truancy, physical fights, bullying) which was not enough to diagnose Conduct disorder. These conduct symptoms were similar between boys and girls but slightly higher in older children. A follow up study found that, of all the conduct symptoms, physical fighting is the best predictor of the onset of Conduct disorder in a child. ${ }^{15}$

Among the respondents with Conduct disorder, majority had Oppositional symptoms ( $>70 \%$ ) and girls showed a slightly higher rate of oppositional behaviors than boys. But aggressive symptoms were common in boys and the difference was highly significant $(\mathrm{p}=.001)$. Among the property offenses, none of the girls had behaviors like breaking in, vandalize or setting fire. But lying and stealing was common among girls. This finding is supported by two studies ${ }^{13,14}$ who concluded that aggression and property offenses were more common among boys, but they also found no gender difference in status offense which is not consistent with the findings of present study. In this study, status offenses (Running away, staying out late, truancy/bunking off) were more common in boys and the difference was statistically significant $(\mathrm{p}=0.05)$. The possible explanation could be that, girls in our society are raised up with caution and girls enjoy much less freedom than their male counter-parts. A girl below 18 is hardly allowed to go out of home alone which is common for boys of similar age. This lack of freedom could be the cause why girls of Bangladesh showed less status offenses than boys. None of the respondents reported of forcing someone into sexual activity and the symptoms like setting fire, breaking in, vandalizing and mugging were less frequently reported which is in concordance with an Indian study who also found these symptoms infrequently which differs from the reports from the Western countries. ${ }^{16}$

This study also showed that aggressive symptoms were more prevalent among younger boys with Conduct disorder than older and the difference was statistically significant, but status offense was slightly more prevalent in older age group. Property offense showed no age difference. This finding is totally consistent with the findings of Maughan et al (2004) who suggested that a substantial age related rise occurs in status violations along with a less marked increase in nonaggressive conduct problems (such as property offense and frequent lying), in contrast physically aggressive symptoms declines with age. ${ }^{14}$

In this study, $48.01 \%$ respondents had at least one comorbid axis-1 psychiatric disorder. A South Korean study found that about $96.9 \%$ adolescent $\mathrm{s}$ with Conduct disorder had psychiatric co-morbidity. ${ }^{17}$ In a four year follow up study, it was reported that among children with ADHD, 65\% had comorbid ODD and 22\% had Conduct Disorder. ${ }^{1}$ Among the co-morbidities, Attention Deficit/Hyperactivity Disorder (ADHD) was found in $43.8 \%$ of children with ODD and $12.3 \%$ with Conduct Disorder. ADHD seemed more strongly linked with oppositional than with conduct symptoms which is supported by the findings of a study who used the similar research instrument in a nationally representative sample of 10,438 children in UK. ${ }^{14}$ The present study found that comorbidity between ODD and ADHD was stronger in girls but no gender difference between Conduct Disorder and ADHD. Maughan et al (2004) also suggested a clear tendency of girls having comorbid ADHD than boys. ${ }^{14}$ Major depressive disorder was present in $22.4 \%$ of conduct disorder and in $3.1 \%$ of ODD population. On the other hand, Anxiety disorders were more common in ODD than with Conduct Disorder ( $25 \%$ versus $8 \%$ ). Depressive disorders showed clear girl preponderance but anxiety disorders did not. These finding are congruent with Maughan et al (2004) except one fact that they found anxiety disorder more common in girls.

\section{Conclusion:}

Despite a number of limitations, this study provided base line data in the field of childhood behavioural problems in Bangladesh. This was the first study to explore the symptom profiles and common comorbidities of ODD and Conduct disorder in Bangladesh which will help in the management of Conduct disorder and ODD. Symptom analysis revealed that type of behavioural problems varies with age and gender and 
researcher recommends that treatment modules can be developed according to symptom presentation. The study has used validated instruments and detailed measures and the findings can be used in future studies yet the researchers should view the findings as provisional and approximate.

\section{References:}

1. Biederman J, Faraone S V., Milberger S, Jetton JG, Chen L, Mick E, et al. Is Childhood Oppositional Defiant Disorder a Precursor to Adolescent Conduct Disorder? Findings from a Four-Year Follow-up Study of Children with ADHD. J Am Acad Child Adolesc Psychiatry [Internet]. 1996;35(9):1193-204. Available from: http:// linkinghub.elsevier.com/retrieve/pii/S0890856709634948

2. American Psychiatric Association. (2000). Diagnostic and Statistical Manual of Mental Disorders (4th ed. text rev. ). Washington, DC: American Psychiatric Association

3. Moffitt T, Scott S. Conduct disorders in childhood and adolescence. In M Rutter, D Bishop,D Pine, S Scott, J Stevenson, E Taylor eds. Rutter's Child and Adolescent Psychiatry. 12th ed. Blackwell publishing; 2008. p. 54364.

4. Fergusson DM, Horwood LJ, Ridder EM. Show me the child at seven: The consequences of conduct problems in childhood for psychosocial functioning in adulthood. J Child Psychol Psychiatry Allied Discip. 2005;46(8):837-49.

5. Belfer ML. Child and adolescent mental disorders: The magnitude of the problem across the globe. J Child Psychol Psychiatry Allied Discip. 2008;49(3):226-36.

6. Patel V, Araya R, Chatterjee S, Chisholm D, Cohen A, De Silva M, et al. Treatment and prevention of mental disorders in low-income and middle-income countries. Lancet. 2007;370(9591):991-1005.

7. Mullick MSI, Goodman R. The prevalence of psychiatric disorders among 5-10 year olds in rural, urban and slum areas in Bangladesh: An exploratory study. Soc Psychiatry Psychiatr Epidemiol. 2005;40(8):663-71.

8. Rabbani MG, Alam MF, Ahmed HU et al. Prevalence of mental disorders, mental retardation, epilepsy and substance abuse in children. Bang J of Psychiatry. 2009;23:11-52

9. Frick PJ, Lahey BB, Applegate B, Kerdyck L, Ollendick T, Hynd GW, et al. DSM-IV Field Trials for the Disruptive Behavior Disorders: Symptom Utility Estimates. J Am Acad
Child Adolesc Psychiatry. 1994;33(4):529-39.

10. Pardini DA, Fite PJ. Symptoms of conduct disorder, oppositional defiant disorder, attention-deficit/ hyperactivity disorder, and callous-unemotional traits as unique predictors of psychosocial maladjustment in boys: Advancing an evidence base for DSM-V. J Am Acad Child Adolesc Psychiatry [Internet]. 2010;49(11):1134-44. Available from: http://dx.doi.org/10.1016/j.jaac.2010. 07.010

11. Burke JD, Hipwell AE, Loeber R. Dimensions of Oppositional Defiant Disorder as Predictors of Depression and Conduct Disorder in Preadolescent Girls. J Am Acad Child Adolesc Psychiatry [Internet]. 2010;49(5):484-92. Available from: http://dx.doi.org/10.1016/j.jaac.2010. 01.016

12. Baker-Henningham H, Scott S, Jones $\mathrm{K}$, Walker S. Reducing child conduct problems and promoting social skills in a middle-income country: Cluster randomised controlled trial. Br J Psychiatry. 2012;201(2):101-8.

13. Lahey BB, Schwab-Stone M, Goodman SH, Waldman ID, Canino G, Rathouz PJ, et al. Age and gender differences in oppositional behavior and conduct problems: A crosssectional household study of middle childhood and adolescence. J Abnorm Psychol. 2000;109(3):488-503.

14. Maughan B, Rowe R, Messer J, Goodman R, Meltzer H. Conduct Disorder and Oppositional Defiant Disorder in a national sample: Developmental epidemology. J Child Psychol Psychiatry. 2004;45(3):609-21.

15. Loeber R, Green SM, Keenan K, Lahey BB. Which Boys Will Fare Worse? Early Predictors of the Onset of Conduct Disorder in a Six-Year Longitudinal Study. J Am Acad Child Adolesc Psychiatry [Internet]. 1995;34(4):499-509. Available from: http://dx.doi.org/10.1097/00004583199504000-00017

16. Jayaprakash R, Rajamohanan K, Anil P. Determinants of symptom profile and severity of conduct disorder in a tertiary level pediatric care set up: A pilot study. Indian J Psychiatry [Internet]. 2014;56(4):330-6. Available from: h t t p ://www.ncbi.n 1 m.nih.gov/pubmed/ $25568472 \% 5$ Cnhttp://www.pubmedcentral.nih.gov/ articlerender.fcgi?artid=PMC4279289

17. Choi BS, Kim JI, Kim BN, Kim B. Comorbidities and correlates of conduct disorder among male juvenile detainees in South Korea. Child Adolesc Psychiatry Ment Health. 2017;11(1):1-7. 